\title{
Role of IFN- $\gamma$ and LPS on neuron/glial co-cultures infected by Neospora caninum
}

\author{
Erica Etelvina Viana De Jesus ${ }^{1}$, Alex Barbosa Dos Santos ${ }^{1}$, Catia Suse Oliveira Ribeiro ${ }^{1}$, \\ Alexandre Moraes Pinheiro ${ }^{2}$, Songeli Menezes Freire ${ }^{3}$, Ramon Santos El-Bachá', \\ Silvia Lima Costa ${ }^{1}$ and Maria de Fatima Dias Costa ${ }^{1 *}$

\begin{abstract}
Laboratório de Neuroquímica e Biologia Celular, Instituto de Ciências da Saúde, Universidade Federal da Bahia-UFBA, Salvador, Brazil
${ }^{2}$ Laboratório de Bioquímica e Imunologia Veterinária, Centro de Ciências Agrárias Ambientais e Biológicas, Universidade Federal do Recôncavo da Bahia, Cruz das Almas, Brazil

${ }^{3}$ Laboratório de Imunologia e Biologia Molecular, Instituto de Ciências da Saúde, Universidade Federal da Bahia-UFBA, Salvador, Brazil
\end{abstract}

\section{Edited by:}

Rubem C.A. Guedes, Universidade

Federal de Pernambuco, Brazil

Reviewed by:

Carme Sola, Instituto de

Investigaciones Biomédicas de

Barcelona-CSIC, Spain

Young-Ji Shiao, National Research

Institute of Chinese Medicine,

Taiwan

*Correspondence:

Maria de Fatima Dias Costa, Laboratório de Neuroquímica e

Biologia Celular, Instituto de

Ciências da Saúde, Universidade

Federal da Bahia-UFBA, Av. Reitor

Miguel Calmon s/n, Vale do Canela, CEP 40110-902, Salvador, Brazil

e-mail: fatima@ufba.br
Neospora caninum causes cattle abortion and neurological symptoms in dogs. Although infection is usually asymptomatic, classical neurological symptoms of neosporosis may be associated with encephalitis. This parasite can grow in brain endothelial cells without markedly damages, but it can modulate the cellular environment to promote its survival in the brain. In previous studies, we described that IFN- $\gamma$ decreased the parasite proliferation and down regulated nitric oxide (NO) production in astrocyte/microglia cultures. However, it remains unclear how glial cells respond to $N$. caninum in the presence of neurons. Therefore, we evaluated the effect of $300 \mathrm{IU} / \mathrm{mL}$ IFN- $\gamma$ or $1.0 \mathrm{mg} / \mathrm{mL}$ of LPS on infected rat neuron/glial co-cultures. After $72 \mathrm{~h}$ of infection, LPS did not affect the mitochondrial dehydrogenase activity. However, IFN- $\gamma$ decreased this parameter by 15.5 and $12.0 \%$ in uninfected and infected cells, respectively. The number of tachyzoites decreased 54.1 and $44.3 \%$ in cells stimulated with IFN- $\gamma$ and LPS, respectively. Infection or LPS treatment did not change NO production. On the other hand, IFN- $\gamma$ induced increased nitrite release in $55.7 \%$, but the infection reverted this induction. IL-10 levels increased only in infected cultures (treated or not), meanwhile $\mathrm{PGE}_{2}$ release was improved in IFN- $\gamma /$ infected or LPS/infected cells. Although IFN- $\gamma$ significantly reduced the neurite length in uninfected cultures (42.64\%; $p<0.001)$, this inflammatory cytokine reverted the impairment of neurite outgrowth induced by the infection (81.39\%). The results suggest a neuroprotective potential response of glia to $N$. caninum infection under IFN- $\gamma$ stimulus. This observation contributes to understand the immune mediated mechanisms of neosporosis in central nervous system (CNS).

Keywords: Neospora caninum, neuron/glial co-culture, immune response, parasite NO downmodulation, neurite impairment

\section{INTRODUCTION}

Neospora caninum is a protozoan that causes cattle abortion and neurological symptoms in dogs (Wouda et al., 1998; Dubey, 1999; Jolley et al., 1999). Classical neurological symptoms are related with severe multifocal necrotizing encephalitis associated with mononuclear cell infiltration (Malaguti et al., 2012). However $N$. caninum infection is generally latent and asymptomatic, due to a formation of cysts with bradyzoites (chronic and latent parasite stage) that can be found in any organ, but is more frequently found in animal brains (Kobayashi et al., 2001; Dubey et al., 2004, 2007).

The blood-brain barrier (BBB) protects the brain against exogenous agents and is constituted by physical, metabolic, and active mechanisms (El-Bachá and Minn, 1999). However, this parasite overcomes these mechanisms and is able to infect glial cells inducing an immune regulation during protozoan infection in central nervous system (CNS) tissues (Yamane et al., 2000;
Pinheiro et al., 2006a,b). Recently, Elsheikha et al. (2013) showed that $N$. caninum is able to grow in brain microvascular endothelial cells (fundamental component of the BBB) without markedly disrupting their normal proliferation or mitochondrial integrity and it was associated with an increase in infected cell respiration.

The immunopathogenesis of neosporosis is complex and only partially understood. Considering any intracellular microbial agent, cellular stress increases as the infection progresses, and host cells normally develop strategies to compensate it by metabolic shifts as an attempt to maintain energy homeostasis and cell viability, avoiding tissue damages (Elsheikha et al., 2013). Inflammatory mediators can modulate the physiology of the BBB during parasite infection, which could play important roles in CNS inflammation (Abbott, 2005). Buxton et al. (2002) and Hemphill et al. (2006) discussed that the progression of $N$. caninum infection was directed related with a balance between the tachyzoite's ability to penetrate and multiply into host cells and 
the host's ability to inhibit parasite multiplication. To clarify the pathogenesis and immune response to this parasite, some authors have studied these mechanisms in cells of the CNS. Yamane et al. (2000) observed a reduction in tachyzoite numbers in bovine cerebellar cells previously infected and stimulated with IFN- $\gamma$ and TNF- $\alpha$. However, the mechanism of proliferation inhibition remained unclear, except by determining that it should be independent of nitric oxide (NO) release. Despite this, the production of NO by peripheral immune response may favor the parasite penetration in the brain, since free radicals induce endothelial permeability changes (Lagrange et al., 1999).

Following these findings, Pinheiro et al. (2006a,b) proposed a rat astrocyte primary culture as a new model to study $N$. caninum infection in vitro. These authors observed that parasite stimulated astrogliosis and production of IL-10, TNF- $\alpha$ and NO. Thereafter, these authors found similar results with mixed cultures of astrocytes and microglia, observing the production of high levels of IL-6 and no detection of IFN- $\gamma$ (Pinheiro et al., 2010).

In vitro experiments have revealed that astrocytes are necessary to establish the expression of several proteins and enzymes by brain endothelial cells (Bart et al., 2000). Therefore, infected astrocytes could interfere in the BBB function. Accurate knowledge about interactions between neuron and glial cells and $N$. caninum is required to learn how the infection can disturb the brain homeostasis. Recent studies of our research group proved that the stimulation of glial cells (astrocyte and microglia) with IFN- $\gamma$ and TNF- $\alpha$ controlled the parasite proliferation independent of NO production, since it was synergically inhibited by IFN- $\gamma$ and tachyzoites. Additionally, an increase in $\mathrm{PGE}_{2}$ release was observed in infected cultures, while IL-10 and TGF- $\beta$ depletion seems to play a possible role on parasite persistence in infected cells. Moreover, while both regulatory cytokines did not interfere in the modulation of NO synthesis, IL-10 could stimulate the release of $\mathrm{PGE}_{2}$ (Jesus et al., 2013).

To continue these studies, it is necessary to understand how glial cells respond to $N$. caninum infection when neurons are present. Some studies have showed that glia can affect neurons by releasing neurotransmitters and other extracellular signaling molecules. Indeed, it is known that the interplay between resident cells of the CNS and peripheral immune response is complex and it can lead to neurotoxic or neuroprotecting effects (reviewed by Kerschensteiner et al., 2009). On the other hand, the parasite could also act in the modulation of this response. As suggested by Elsheikha et al. (2013), it is possible that the parasite could modify the cellular environment to promote its own intracellular survival.

This is necessary to understand how the interaction between $N$. caninum, neurons and glial cells affects immunopathogenic mechanisms and the response to infection. Therefore, the aim of the present study was to evaluate the effect of inflammatory stimulus (IFN- $\gamma$ and LPS) on neuron/glial co-cultures infected with $N$. caninum in order to understand aspects of mediators release and their influence on neurotoxic/neuroprotective effects induced by the parasite infection.

\section{MATERIAL AND METHODS \\ NEURON/GLIAL CO-CULTURES}

Mixed glial cells (astrocytes and microglia) were first obtained from brain cortices of newborn rats ( $<48 \mathrm{~h}$ of age) by mechanical dissociation of the tissue. The cultures were maintained in Dulbecco's modified Eagle's medium-F12 (DMEM-F12) supplemented with $10 \% \quad(\mathrm{v} / \mathrm{v})$ fetal bovine serum, $100 \mathrm{IU} / \mathrm{mL}$ penicillin $\mathrm{G}, 100 \mathrm{~g} / \mathrm{mL}$ streptomycin, $2 \mathrm{mM}$ L-glutamine, $0.011 \mathrm{~g} / \mathrm{L}$ pyruvate, $3.6 \mathrm{~g} / \mathrm{L}$ Hepes and $12 \mathrm{mM}$ glucose, incubated at $37^{\circ} \mathrm{C}$ in a humid atmosphere with $5 \% \mathrm{CO}_{2}$. All of these reagents were purchased from Gibco/Invitrogen.

These cultures were initially seeded onto culture dishes with the diameter of $100 \mathrm{~mm}$ (TPP, Switzerland) and after 14 days, they were re-seeded $\left(5 \times 10^{4}\right)$ in tissue culture plates with 24 -wells for assays. This culture was previously characterized as containing about $86 \%$ of astrocytes and $12 \%$ of microglia (Pinheiro et al., 2010).

At this time, embryos were removed from pregnant rats on the 17 th or 18 th gestational day by cesarian section. Cells were dissociated from embryo brain cortices in DMEM/F-12 as described above. Neurons $\left(2.5 \times 10^{4} /\right.$ well $)$ were plated on astrocyte/microglia monolayer and the cultures were maintained with regular DMEM/F-12 changed every 48 h for 7 days, when the experiments were performed. All animal procedures were performed in accordance with the local Ethical Committee for Animal Experimentation.

\section{CULTURE OF NEOSPORA CANINUM}

$N$. caninum tachyzoites of the $\mathrm{NC}-1$ strain were maintained in Vero cells in RPMI 1640 medium (Gibco BRL, USA) supplemented with $10 \%(\mathrm{v} / \mathrm{v})$ fetal bovine serum (Gibco BRL, USA), $100 \mathrm{IU} / \mathrm{mL}$ penicillin $\mathrm{G}$ and $100 \mathrm{~g} / \mathrm{mL}$ streptomycin (CULTILAB, Brazil). To obtain the parasites, the Vero cells were first washed with phosphate buffered saline (PBS) and then mechanically disrupted. Thereafter, tachyzoites were purified using a $5.0 \mu \mathrm{m}$ filter (Millipore, Carrigtwohill, Ireland) as described by Pinheiro et al. (2010).

\section{NEURON/GLIAL CO-CULTURE INFECTION AND TREATMENT}

Neuron/Glial co-cultures were treated with $300 \mathrm{IU} / \mathrm{mL}$ of recombinant rat IFN- $\gamma$ (R\&D Systems, USA) or $1.0 \mathrm{mg} / \mathrm{mL}$ of LPS from Escherichia coli 0111:B4 (Sigma-Aldrich, USA) diluted in culture medium. Cells were treated only with fresh medium in control conditions. Twenty-four hours after treatment, neuron/glial co-cultures were infected with tachyzoites of $N$. caninum (host:parasite ratio of 1:1). Analyses were performed 72 $\mathrm{h}$ post-infection as determined in previous studies (Jesus et al., 2013).

\section{MTT ASSAY}

The MTT [3-(4,5-dimethylthiazol-2-yl)-2,5-diphenyl tetrazolium bromide] assay was performed to evaluate the energetic metabolic activity of cells. The assay is based in the ability of alive cells to convert yellow MTT in purple formazan crystals by mitochondrial dehydrogenases. The experiment was performed in 96-well plates (TPP, Switzerland). Briefly, cells $\left(1 \times 10^{4}\right.$ cells/well $)$ 
under different culture conditions were incubated with MTT at a final concentration of $1.0 \mathrm{mg} / \mathrm{mL}$ for $2 \mathrm{~h}$. Thereafter, cells were lyzed with $20 \%(\mathrm{w} / \mathrm{v})$ sodium dodecyl sulfate (SDS), 50\% (v/v) dimethyl formamide (DMF) ( $\mathrm{pH} 4.7)$, and plates were kept overnight at $37^{\circ} \mathrm{C}$ in order to dissolve formazan crystals. The optical density was quantified at $580 \mathrm{~nm}$ (Hansen et al., 1989). Three independent experiments were carried out with eight replicate wells for each analysis. Results are shown as mitochondrial activity percentage compared to untreated/uninfected control cultures, considered as $100 \%$.

\section{DETERMINATION OF PARASITE NUMBER}

To quantify the parasite in cultures, the number of tachyzoites was counted in each culture $72 \mathrm{~h}$ after infection. To ensure that all parasites (intra- and extracellular) were counted, culture monolayers were scraped with their culture media, the cells were ruptured by three passages through a 22-gauge needle and tachyzoites were counted using a hemocytometer, as described by Yamane et al. (2000). Three independent experiments were performed in triplicate by two independent investigators in a blind assay. The results are expressed as the mean of tachyzoite percentages compared with the untreated control cultures (considered as $100 \%)$.

\section{MEASUREMENT OF NITRITE LEVELS}

Supernatants from neuron-glial co-cultures were assayed in triplicate for nitrite content, which reflects NO production, using the Griess reagent ( $1 \%$ sulfanilamide and $0.1 \%$ naphthyl-ethylenediamine dihydrochloride in $2.5 \%$ phosphoric acid in equal volumes). After $15 \mathrm{~min}$ of incubation at room temperature, the absorbance was measured at $560 \mathrm{~nm}$ using a microtiter plate reader (Biotek instruments, Inc., USA). Nitrite concentrations were calculated by comparison with a standard calibration curve of sodium nitrite $\left(\mathrm{NaNO}_{2}: 1.26-100 \mathrm{mM} / \mathrm{L}\right)$ with DMEM-F12 as the baseline control.

\section{PGE2 LEVELS DETERMINATION}

Culture supernatants from the different treatments were assayed for $\mathrm{PGE}_{2}$ levels using an enzyme immunoassay kit (Cayman Chemical Co., USA), according to manufacturer instructions. This assay has a detection limit of $15 \mathrm{pg} / \mathrm{mL}$.

\section{CYTOKINES DETERMINATION}

TNF- $\alpha$ and IL-10 were measured in the culture supernatants by using a commercial kit (Sandwich ELISA, R\&D, USA), according to manufacturer instructions. Cell culture medium (three samples of three independent experiments) was collected $72 \mathrm{~h}$ after infection, centrifuged at $3500 \mathrm{~g}$ during $5 \mathrm{~min}$ and stored at $-70^{\circ} \mathrm{C}$ until the time of assay. Results are expressed as percentage of concentration means compared to untreated control cultures, considered as $100 \%$.

\section{MORPHOMETRY ANALYSIS}

$\beta$-III tubulin immunocytochemistry was performed to detect neurites. Cells were incubated with mouse monoclonal anti- $\beta$ III tubulin (Santa Cruz Biotechnology Inc., USA) diluted 1:400 in TBS (tris buffer solution), overnight at $4^{\circ} \mathrm{C}$ in a humid chamber. Then, these cells were incubated with goat anti-mouse IgG peroxidase (1/400 in TBS, Bio-Rad, Hercules, CA) and the immunoreactivity was visualized using a peroxidase-conjugated substrate kit according to manufacturer's instructions (Bio-Rad, Hercules, CA). Co-staining (a blue panchromic differential staining to nuclei and other cytoplasmic components) was performed by using the protocol established by Rosenfeld (1947). The Rosenfeld's reagent $(1 \mathrm{~mL})$ was added and incubated for $20 \mathrm{~min}$ at room temperature. Thereafter, the plates were rinsed with water, air dried, analyzed and photographed in an optical phase microscope (Nikon TS-100) using a digital camera (Nikon E4300).

Neurite lengths were determined using NIH software Image J, with Neuron J plug-in (Copyright from Erik Meijering). Three independent experiments were performed and neurites of each neuron were measured in five randomly chosen fields per sample. Results are shown as percentage of mean total neurite length compared to untreated/infected control neurons, considered as $100 \%$.

\section{Statistical analysis}

The results are expressed as the mean \pm the standard deviation (SD). The comparisons between the experimental groups and the corresponding controls were performed with GraphPad Prism 6 for Mac OS X (GraphPad Software, Inc.) using a two-way ANOVA, except to parasite number evaluation that one-way ANOVA followed by a Tukey post-test was performed. Probability values (p) of 0.05 or less were considered significant.

\section{RESULTS}

\section{IFN- $\gamma$ DECREASED THE MITOCHONDRIAL ACTIVITY}

MTT assay was performed to evaluate whether the experimental treatment with cytokines induced a metabolic challenge to cells. Under experimental conditions, untreated and LPS-treated cultures (infected or not) did not show reduction in mitochondrial dehydrogenase activities. However, IFN- $\gamma$ decreased mitochondrial dehydrogenase activities by 15.5 in uninfected cells (Figure 1).

\section{IFN- $\gamma$ AND LPS DECREASED THE PARASITE NUMBER}

The inflammatory microenvironment in neuron/glial co-cultures induced by the experimental treatment reduced the parasite number. After $72 \mathrm{~h}$ of infection, the number of $N$. caninum tachyzoites decreased 54.1 and $44.3 \%$ in cells stimulated with IFN- $\gamma$ and LPS, respectively (Figure 2 ).

\section{IFN- $\gamma$ INDUCED NO PRODUCTION, BUT THE PARASITE ABOLISHED THIS EFFECT}

Nitrite levels were measured in culture media under inflammatory stimulus as a parameter to evaluate NO production. In untreated/infected cultures, the nitrite concentration in supernatant did not change. As expected, IFN- $\gamma$ induced NO production (increased 55.7\%) in uninfected cultures, but the infection decreased this induction, significantly. Meanwhile, LPS stimulus did not change nitrite levels compared with control conditions (Figure 3A). 

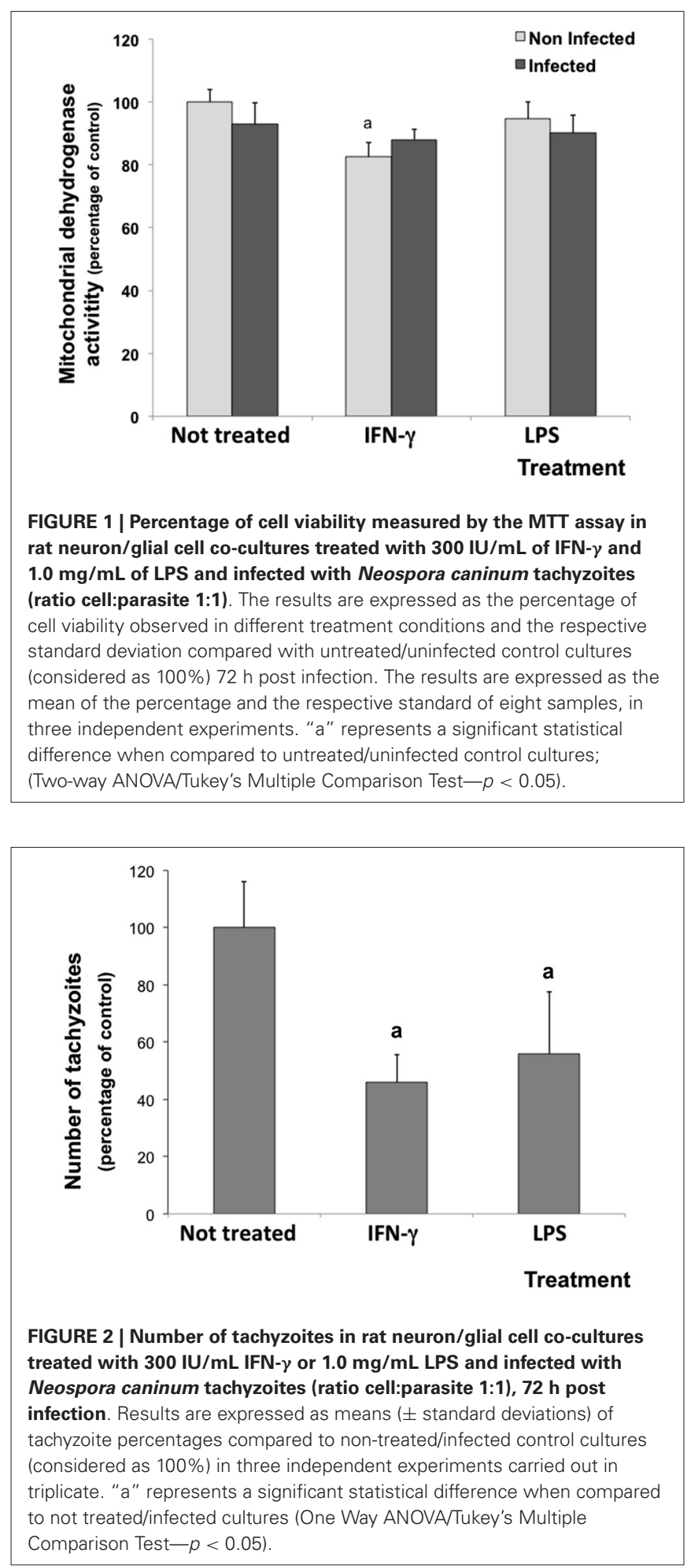

\section{IFN- $\gamma$ AND LPS INDUCED PGE 2 RELEASE IN INFECTED CELLS}

Culture media were also assayed for $\mathrm{PGE}_{2}$ levels. Although the inflammatory treatment with IFN- $\gamma$ or LPS did not change the $\mathrm{PGE}_{2}$ release in uninfected cells, levels increased by $70.4 \%$ and $86.5 \%$ in IFN- $\gamma$-treated/infected and in LPS-treated/infected

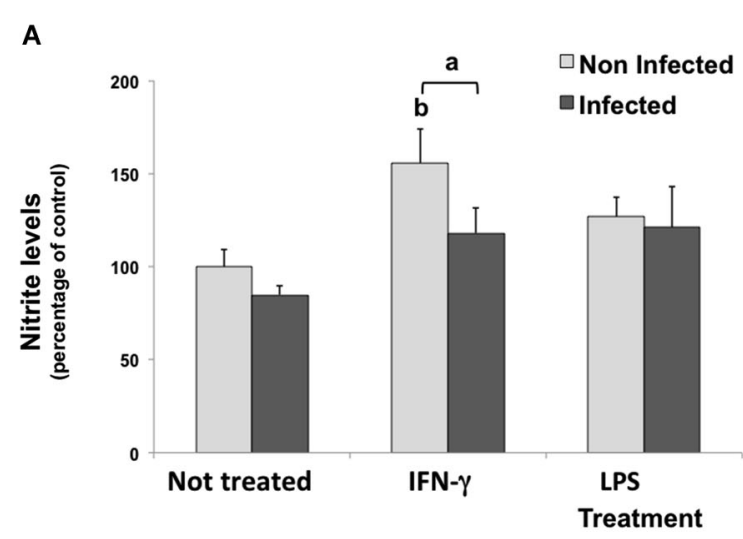

B

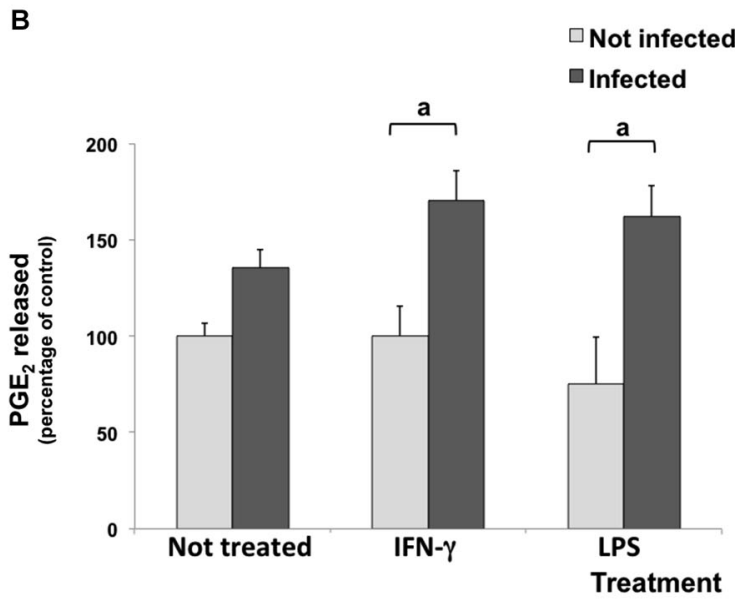

FIGURE 3 | Nitrite (A) and Prostaglandin E2 (PGE $)$ (B) levels in culture media of rat neuron/glial cell co-cultures treated with $300 \mathrm{IU} / \mathrm{mL}$ of IFN- $\gamma$ and $1 \mathrm{mg} / \mathrm{mL}$ of LPS and infected with Neospora caninum tachyzoites (ratio cell:parasite 1:1), $72 \mathrm{~h}$ post infection. Results are expressed as the means $\left( \pm S D\right.$ ) of the percentage of nitrite $(\mathbf{A})$ or $P G E_{2}$ (B) compared to control conditions (considered as 100\%) in three independent experiments carried out in triplicate. "a" represents a significant statistical difference between the same treatment group; " $b$ " represents a significant statistical difference when compared to untreated/uninfected control cultures (Two-way ANOVA/Tukey's Multiple Comparison Test- $p<0.05$ ).

cultures, when compared to IFN- $\gamma$ and LPS treated cultures, respectively (Figure 3B).

\section{LPS INCREASED THE RELEASE OF TNF- $\alpha$ AND LPS INCREASED THE RELEASE OF IL-10}

To investigate glial immune response in this culture infection model, the release of TNF- $\alpha$ and IL-10 cytokines was measured in cell culture supernatants (Figure 4). The infection or the IFN$\gamma$ treatment did not change the basal level of TNF- $\alpha$ measured in untreated/uninfected control cultures. However, the LPS treatment significantly increased TNF- $\alpha$ release both in uninfected and infected cultures (Figure 4A).

In infected cultures, the IL-10 amount in supernatant increased about $45 \%$ when compared with untreated/uninfected cultures (Figure 4B). However, IFN- $\gamma$ and LPS did not change it. 


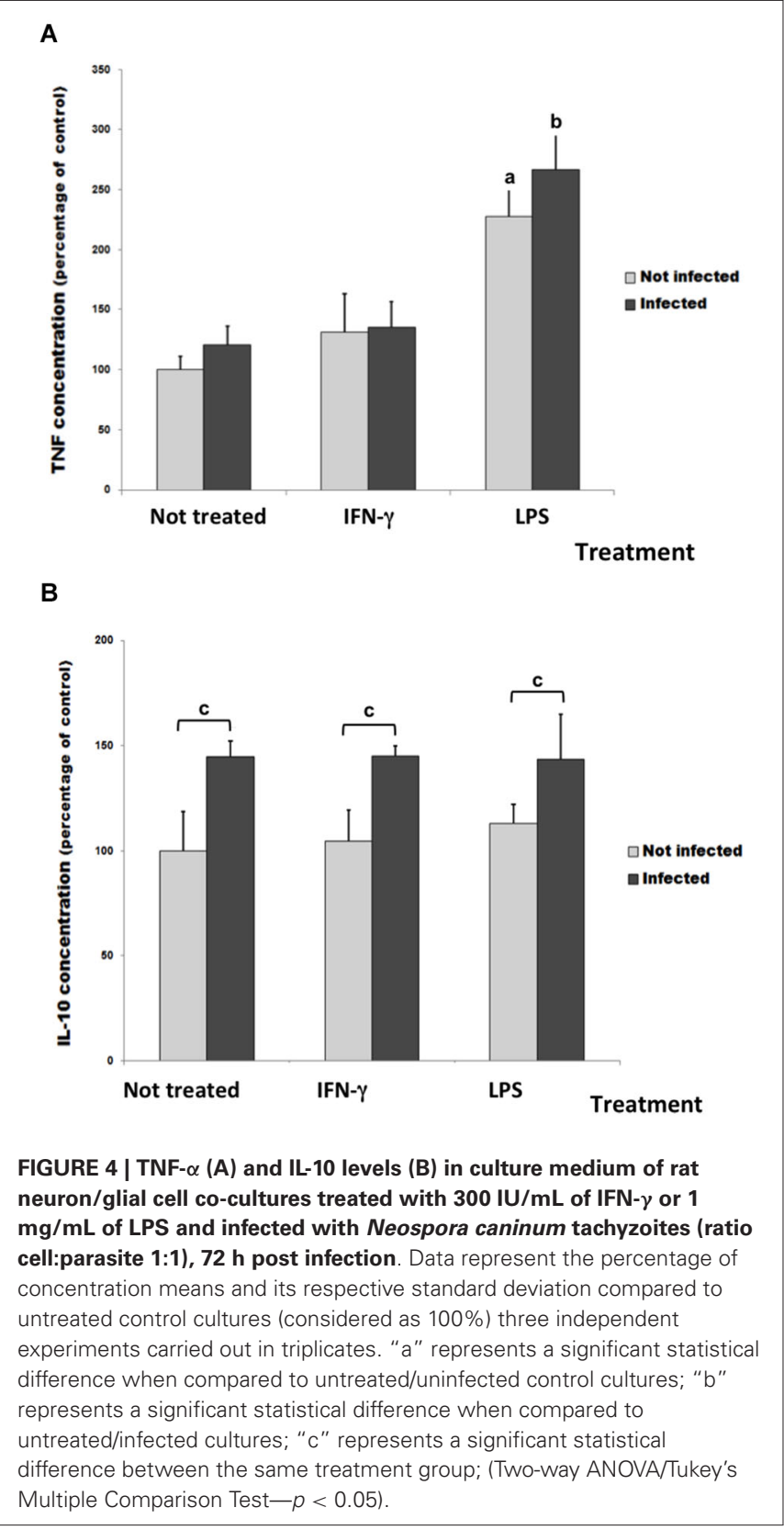

IFN- $\gamma$ RESTORED NEURITE OUTGROWTH IN INFECTED CELLS

In this study, neurite outgrowth length was used as a parameter to evaluate the neuronal ability to maintain the dynamics of the tubulin and actin cytoskeletons (Figure 5), which is essential for the establishment of synapses. The basal neurite length under control conditions was considered as $100 \%$. Untreated/infected neuron/glial co-cultures showed a drastic impairment of neurite outgrowth (reduction of $51.47 \% ; p<0.001$ ), which can represent a possible deleterious effect of parasite infection. Although IFN$\gamma$ significantly reduced the neurite length in uninfected cultures $(42.64 \% ; p<0.001)$, this inflammatory cytokine reverted the impairment of neurite outgrowth induced by the infection $(81.39 \%)$.
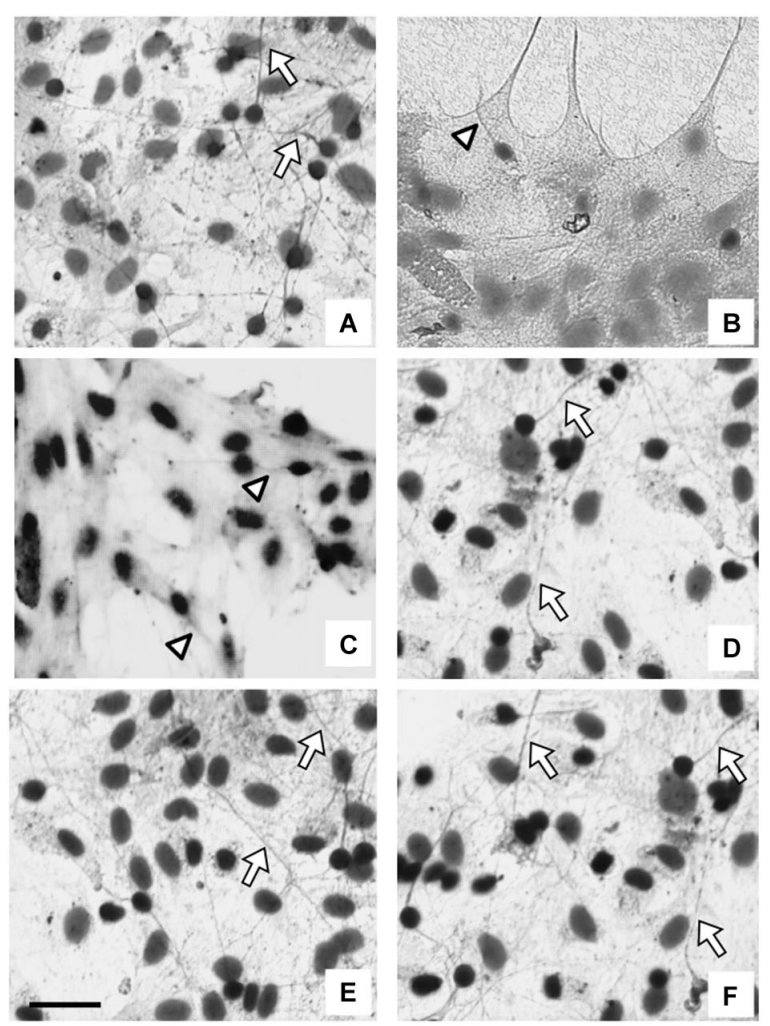

G

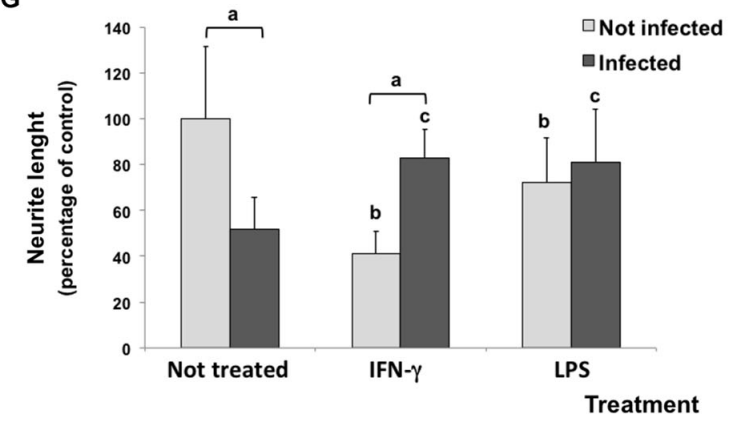

FIGURE 5 | Immunodetection (immunoperoxidase) of tubulin $\beta$ III of rat neuron/glial cells co-culture treated with $300 \mathrm{IU} / \mathrm{mL}$ of IFN- $\gamma$ and $1 \mathrm{mg} / \mathrm{mL}$ of LPS and infected with Neospora caninum tachyzoites (ratio cell:parasite 1:1), $72 \mathrm{~h}$ post infection. Control cells maintained in fresh medium exhibit a basal neurite outgrowth (arrow) (A); a drastic impairment of neurite (arrowhead) was observed in N. caninum infected culture (B) and IFN- $\gamma$ treated cells (C); neurite length (arrow) in

IFN- $\gamma /$ infected cultures (D); LPS/uninfected and LPS/infected cells did not exhibit changes in neurite lenght $(\mathbf{E}, \mathbf{F})$. Scale bar $=50 \mu \mathrm{m}$.

(G) Measurement and statistical analysis of neurite length (percentage of control) and its respective standard deviation compared to

untreated/uninfected cultures (considered as 100\%) in three samples in three independent experiments. "a" represents a significant statistical difference between the same treatment group; " $b$ " represents a significant statistical difference when compared to untreated/uninfected control cultures; " $c$ " represents a significant statistical difference when compared to untreated/infected cultures (Two-way ANOVA/Tukey's Multiple Comparison Test $-p<0.05)$.

A similar result was observed in LPS treated cultures. While neurite length reduced in LPS treated/uninfected cultures (72.3\%; 
$p<0.001$ ), LPS also inhibited a further impairment of neurite outgrowth induced by the infection (increase of $29.4 \%$ when compared with untreated/infected cultures).

\section{DISCUSSION}

Previous studies of our group described that astrocyte/microglia cultures infected with $N$. caninum presented a decreased parasite proliferation, release of $\mathrm{PGE}_{2}$ and down modulation of NO after IFN- $\gamma$ stimulation (Jesus et al., 2013). These events were associated with a parasite escape mechanism and an anti-inflammatory pattern of response by infected glial cells, suggesting a possible glial protective role on nervous tissue during this parasite infection. However, the knowledge of these response effects in the presence of neurons remains unclear. In this study, we have studied the glial response to $N$. caninum infection in a neuron/glial co-culture model and their consequences.

Different from previously observed in astrocyte/microglia mixed cultures, neuron/glial co-cultures showed reduced mitochondrial dehydrogenase activities when stimulated with 300 IU/mL IFN- $\gamma$, independent of infection. Therefore, this suggests a toxic effect of this cytokine on neuron/glial co-cultures, affecting the mitochondrial function.

The $\mathrm{BBB}$ is more than a physical barrier constituted by tight junctions of brain endothelial cells. Enzymes involved in the detoxification of the metabolism of numerous endogenous and exogenous compounds, such as UDP-glucuronyltransferases (EC 2.4.1.17), are expressed in microsomes of the brain (ElBachá et al., 2000), constituting a metabolic barrier. Furthermore, some studies have shown that reactive astrocytes release a wide array of mediators, including pro- and antiinflammatory cytokines, neurotrophic or neurotoxic factors, chemokines, complement factors and reactive oxygen species (ROS; Liberto et al., 2004; Farina et al., 2007; Sofroniew and Vinters, 2010; Allaman et al., 2011). This means that there is also an immunological barrier protecting neurons against biological agents. We previously showed that N. caninum induced the expression of IL-10 in rat astrocyte primary cultures, but these cells did not release IFN- $\gamma$ (Pinheiro et al., 2006b). However, IFN- $\gamma$ is one of the most important cytokines involved in the control of $N$. caninum growth, because IFN- $\gamma$-deficient mice succumb to acute infection with tachyzoites (Nishikawa et al., 2001). Moreover, IFN- $\gamma$ inhibited N. caninum growth in human astrocytoma cells (Spekker et al., 2009). In the present work, IFN- $\gamma$ decreased the activity of mitochondrial dehydrogenases even in uninfected cells. Therefore, this may challenge neurons.

On the other hand, the inflammatory stimulus was able to reduce the parasite number in infected neuron/glial co-culture. Some previous studies have shown reduction in tachyzoite number mediated by inflammatory stimulus both in vitro and in vivo (Innes et al., 1995, 2000; Khan et al., 1997; Tanaka et al., 2000). In brain cells, Yamane et al. (2000) showed that IFN- $\gamma$ and TNF- $\alpha$ inhibited the parasite growth in bovine cerebellar cells in vitro. Similarly, previous findings of our research group (Jesus et al., 2013) had already obtained a similar result in primary cultures of glial cells (astrocytes and microglia).
A large number of studies have shown the role of IFN- $\gamma$ in controlling $T$. gondii proliferation, but the exact mechanism that promotes this anti-parasitic effect remains uncertain (Jun et al., 1993; Halonen et al., 1998, 2001; Halonen and Weiss, 2000; Freund et al., 2001; Scheidegger et al., 2005; Delair et al., 2009). Some evidences indicate that cytokines, mainly IFN- $\gamma$, can also activate astrocytes to inhibit the growth of T. gondii, but the mechanism of inhibition remains to be elucidated (Halonen et al., 1998). These authors showed that this event is not due to NO production and that the addition of tryptophan had no effect on inhibition, indicating that the mechanism was not mediated via indoleamine 2,3-dioxygenase (IDO) induction.

In the same way, studies about the role of IFN- $\gamma$ in controlling N. caninum proliferation are controversial. Tanaka et al. (2000) indicated a NO dependent mechanism as responsible to kill tachyzoites inside macrophages. Using in vivo models, Baszler et al. (1999) showed the role of IFN- $\gamma$ in controlling acute neosporosis in mice. However, the development of encephalitis and parasite proliferation were more related to the absence of IL-4-mediated response than a strong IFN- $\gamma$ response.

The mechanisms involved on the parasite destruction induced by IFN- $\gamma$ cytokine or other inflammatory stimuli still need to be clarified. Vonlaufen et al. (2002) reported that after 5 days of infection with N. caninum tachyzoites, IFN- $\gamma$ treated slices of CNS organotypic cultures showed only small necrotic pseudocysts and many parasites supposedly dead after cell invasion. However, it is not yet possible to say whether the reduction in the number of tachyzoites reported in this study was due to a reduction in the invasiveness of the parasite and/or an increased ability to destroy the infected cells in their cytoplasm.

This study did not observe a reduction on nitrite levels in the supernatant of infected co-cultures. This disagrees with our previous findings, in which the infection reduced NO release in astrocyte/microglia mixed cultures (Jesus et al., 2013). However, in IFN- $\gamma$ treated co-cultures, the infection reduced NO production. Rozenfeld et al. (2005) provided evidence that the NO production of IFN- $\gamma$-activated microglia is inhibited by T. gondii infection, which appears to favor neuron viability. Previously, Yamane et al. (2000) showed that NMMA (an iNOS selective inhibitor) did not reverse the inhibition of parasite growth by IFN- $\gamma$ in cerebellar bovine cells. Therefore, we can suppose that the parasite reduction in IFN- $\gamma$-stimulated cultures might be induced through other mechanisms than NO. Nevertheless, further studies should be performed to elucidate the NO down-modulation mechanism by the parasite infection on glial cells.

Another possibility to be considered involves the consumption of NO to produce peroxynitrite anion-a potent oxidant and toxic agent-by NADPH oxidase stimulation in glial cells (Minghetti and Levi, 1998; Bal-Price et al., 2002; Brown and BalPrice, 2003). However, peroxynitrite determination was not tested in this study.

These data suggests two interpretations: (1) the reduction in the tachyzoite number promoted by inflammatory stimuli should not be mediated by NO; (2) N. caninum infection in glial cells can induce parasite escape mechanisms, which could, among other things, decrease NO production. A possible direct action 
of the parasite is reinforced by Rozenfeld et al. (2005). These authors observed that in microglia cultures treated with IFN- $\gamma$ the inhibition of iNOS expression was restricted to T. gondii infected cells.

Despite its classic performance as a pro-inflammatory molecule, $\mathrm{PGE}_{2}$ also plays a role in neuronal injury protection by decreasing NO production in activated microglia and modulating proinflammatory events (Aloisi et al., 1999; Zhang and Rivest, 2001). In T. gondii infection it is believed that $\mathrm{PGE}_{2}$ may be especially favorable to nervous tissue, modulating the immune response and contributing to maintain the integrity of brain cells (Rozenfeld et al., 2003).

In this study, we observed an increase in $\mathrm{PGE}_{2}$ released by IFN- $\gamma$-treated/infected and LPS-treated/infected cultures. This fact could be indirectly related with regulatory mechanisms, triggered by inflammatory stimulus, that contribute to NO down modulation in the presence of the parasite. However, further experiments should be conducted to confirm this hypothesis. $\mathrm{PGE}_{2}$ has been also associated with an enhancement of regulatory cytokine secretion, as IL-10. Some studies showed exogenous $\mathrm{PGE}_{2}$ inducing cAMP up-regulation, which leads to TNF- $\alpha$ and IL-12 inhibition and over expression of IL-10 (Aloisi et al., 1997, 1999; Levi et al., 1998; Rozenfeld et al., 2003).

The role of regulatory cytokine IL-10 in inflammatory and infectious diseases has been largely studied, as reviewed by Ouyang et al. (2011). This cytokine can also facilitate the tissuehealing process in injuries caused by infection or inflammation, repressing pro-inflammatory responses and limiting unnecessary tissue disruptions caused by inflammation. In this study, IL-10 was produced only in response to infection. This agrees with previous findings of (Pinheiro et al. (2006b, 2010)) who showed IL-10 overexpression by $N$. caninum infected astrocyte and in microglia/astrocyte cultures.

Due to these facts, a limited involvement of $\mathrm{PGE}_{2}$ and IL-10 on glial responses to infection can be supposed. However, these mediators are only two in a large number of molecules (not yet identified) that act in the complex cellular/molecular interaction during neuroglial response to $N$. caninum infection. Kerschensteiner et al. (2009) propose that the neuro-immune crosstalk in CNS is not determined by single molecules or even classes of individual molecules, but by the integration of multiple signals that individually may favor the destruction or tissue repair.

In neuron/glial co-culture, the parasite infection inhibited drastically neurite outgrowth, showing a N. caninum-mediated neurotoxic effect. This fact could be associated with neurological symptoms and pathological findings in infected animal (Dubey et al., 1998; Poli et al., 1998; Reichel et al., 2007; Dubey and Schares, 2011). In the same way, IFN- $\gamma$ stimulus induced a severe neuronal damage. Fortunately, this cytokine was not detected in infected astrocytes and microglia cultures (Pinheiro et al., 2006b, 2010). Lipopolysaccharide induced the same inflammatory effect in neurite outgrowth. Kitayama et al. (2011) showed neurite outgrowth inhibition by LPS stimulated microglia. Indeed, a combined effect between tachyzoite and these inflammatory stimuli can be supposed, since the neurite length was preserved in IFN- $\gamma$ or LPS treated/infected cultures.
The preservation of neurite outgrowth in IFN- $\gamma$ treated/infected co-cultures can be not associated to an indirect effect of $\mathrm{PGE}_{2}$ and IL-10 secreted by IFN- $\gamma$-treated/infected cells as supposed by Rozenfeld et al. (2003). In this study, $\mathrm{PGE}_{2}$ and IL-10 were also released by untreated/not infected cultures, in which neurite impairment was more evident. A direct effect of neuron parasite infection has to be more studied to clarify how the neurotoxic effect of $N$. caninum infection occurs.

The mechanism by which IFN- $\gamma$-stimulated glia can protect neurons in $N$. caninum infected cultures are still under investigation in our research group. The IFN- $\gamma$ pretreatment could induce astrocyte stored glycogen, which sustains their own energy requirements and enables them to support neighboring neurons through the export of glucose or lactate (Liberto et al., 2004). Other hypothesis is the up regulation of neurotrophic factors by glia-derived cytokines. Nerve growth factor (NGF), brain-derived neurotrophic factor (BDNF), neurotrophin-3 (NT3 ) and glial cell-derived neurotrophic factor (GDNF) are able to promote neuronal survival via tyrosine kinase receptors or inhibition of NO synthetase expression (Barbacid, 1995; Wang et al., 1997).

Much more knowledge are needed to elucidate the immunoregulatory glial role during $N$. caninum infection in the CNS. The results presented here should contribute with this understanding. Under IFN $-\gamma$ stimulus, the parasite reduction number associated with inhibition of $\mathrm{NO}$ production, release of $\mathrm{PGE}_{2}$ and IL-10, and neurite length preservation suggest a neuroprotective response. However, the mechanism triggered by IFN- $\gamma$ stimulus and the parasite infection that leads to neuroprotection needs to be clarified. This observation can contribute to understand immune-mediated mechanisms of neosporosis in the CNS and contribute to further in vivo experiments. Furthermore, it contributes to understand how immunological mechanisms help to protect neurons, especially when the physical, metabolic and other mechanisms of the BBB fail to protect the brain against biological challenges.

\section{ACKNOWLEDGMENTS}

This work was supported in part by grants from Conselho Nacional de Desenvolvimento Científico e Tecnológico (CNPq) and Coordenaçã o de Aperfeiçoamento de Pessoal de Nível Superior (CAPES).

\section{REFERENCES}

Abbott, N. J. (2005). Dynamics of CNS barriers: evolution, differentiation and modulation. Cell. Mol. Neurobiol. 25, 5-23. doi: 10.1007/s10571-004-1374-y

Allaman, I., Bélanger, M., and Magistretti, P. J. (2011). Astrocyte-neuron metabolic relationships: for better and for worse. Trends Neurosci. 34, 76-87. doi: 10.1016/j. tins.2010.12.001

Aloisi, F., De Simone, R., Columba-Cabezas, S., and Levi, G. (1999). Opposite effects of interferon-gamma and prostaglandin E2 on tumor necrosis factor and interleukin-10 production in microglia: a regulatory loop controlling microglia pro- and anti-inflammatory activities. J. Neurosci. Res. 56, 571-580. doi: 10. 1002/(sici)1097-4547(19990615)56:6\&lt;571::aid-jnr3\&gt;3.0.co;2-p

Aloisi, F., Penna, G., Cerase, J., Menéndez, B., and Adorini, L. (1997). IL-12 production by central nervous system microglia is inhibited by astrocytes. $J$. Immunol. 159, 1604-1612.

Bal-Price, A., Matthias, A., and Brown, G. C. (2002). Stimulation of the NADPH oxidase in activated rat microglia removes nitric oxide but induces peroxynitrite production. J. Neurochem. 80, 73-80. doi: 10.1046/j.0022-3042.2001.00675.x 
Barbacid, M. (1995). Structural and functional properties of the TRK family of neurotrophinreceptors. Ann. N Y Acad. Sci. 766, 442-458. doi: 10.1111/j.17496632.1995.tb26693.x

Bart, J., Groen, H. J. M., Hendrikse, N. H., van der Graaf, W. T. A., Vaalburg, W., and de Vries, E. G. E. (2000). The blood-brain barrier and oncology: new insights into function and modulation. Cancer Treat. Rev. 26, 449-462. doi: 10.1053/ctrv. 2000.0194

Baszler, T. V., Long, M. T., McElwain, T. F., and Mathison, B. A. (1999). Interferongamma and interleukin-12 mediate protection to acute Neospora caninum infection in BALB/c mice. Int. J. Parasitol. 29, 1635-1646. doi: 10.1016/s00207519(99)00141-1

Brown, G. C., and Bal-Price, A. (2003). Inflammatory neurodegeneration mediated by nitric oxide, glutamate and mitochondria. Mol. Neurobiol. 27, 325-355. doi: 10.1385/mn:27:3:325

Buxton, D., McAllister, M. M., and Dubey, J. P. (2002). The comparative pathogenesis of neosporosis. Trends Parasitol. 18, 546-552. doi: 10.1016/S14714922(02)02414-5

Delair, E., Creuzet, C., Dupouy-Camet, J., and Roisin, M. P. (2009). In vitro effect of TNF-alpha and IFN-gamma in retinal cell infection with Toxoplasma gondii. Invest. Ophthalmol. Vis. Sci. 50, 1754-1760. doi: 10.1167/iovs.07-1376

Dubey, J. P. (1999). Recent advances in Neosporaand neosporosis. Vet. Parasitol. 84, 349-367. doi: 10.1016/S0304-4017(99)00044-8

Dubey, J. P., Dorough, K. R., Jenkins, M. C., Liddell, S., Speer, C. A., Kwok, O. C. H., et al. (1998). Canine neosporosis: clinical sings, diagnosis, treatment and isolation of Neospora caninumin mice and cell culture. Int. J. Parasitol. 28, 1293-1304. doi: 10.1016/s0020-7519(98)00099-x

Dubey, J. P., and Schares, G. (2011). Neosporosis in animals-The last five years. Vet. Parasitol. 180, 90-108. doi: 10.1016/j.vetpar.2011.05.031

Dubey, J. P., Sreekumar, C., Knickman, E., Miska, K. B., Vianna, M. C., Kwok, O. C., et al. (2004). Biologic, morphologic and molecular characterisation of Neospora caninum isolates from littermate dogs. Int. J. Parasitol. 34, 1157-1167. doi: 10. 1016/j.ijpara.2004.07.005

Dubey, J. P., Vianna, M. C., Kwok, O. C., Hill, D. E., Miska, K. B., Tuo, W., et al. (2007). Neosporosis in Beagle dogs: clinical signs, diagnosis, treatment, isolation and genetic characterization of Neospora caninum. Vet. Parasitol. 149, 158-166. doi: 10.1016/j.vetpar.2007.08.013

El-Bachá, R. S., Leclerc, S., Netter, P., Magdalou, J., and Minn, A. (2000). Glucuronidation of apomorphine. Life Sci. 67, 1735-1745. doi: 10.1016/s00243205(00)00764-5

El-Bachá, R. S., and Minn, A. (1999). Drug metabolizing enzymes in cerebrovascular endothelial cells afford a metabolic protection to the brain. Cell. Mol. Biol. (Noisy-le-grand) 45, 15-23.

Elsheikha, H. M., McKinlay, C. L., Elsaied, N. A., and Smith, P. A. (2013). Effects of Neospora caninum infection on brain microvascular endothelial cells bioenergetics. Parasit. Vectors 6:24. doi: 10.1186/1756-3305-6-24

Farina, C., Aloisi, F., and Meinl, E. (2007). Astrocytes are active players in cerebral innate immunity. Trends Immunol. 28, 138-145. doi: 10.1016/j.it.2007.01.005

Freund, Y. R., Zaveri, N. T., and Javitz, H. S. (2001). In vitro investigation of host resistance to Toxoplasma gondiiinfection in microglia of BALB/c and CBA/Ca mice. Infect. Immun. 69, 765-772. doi: 10.1128/iai.69.2.765-772.2001

Halonen, S. K., Chiu, F., and Weiss, L. M. (1998). Effect of cytokines on growth of Toxoplasma gondii in murine astrocytes. Infect. Immun. 66, 4989-4993.

Halonen, S. K., Taylor, G. A., and Weiss, L. M. (2001). Gamma interferon-induced inhibition of Toxoplasma gondii in astrocytes is mediated by IGTP. Infect. Immun. 69, 5573-5576. doi: 10.1128/iai.69.9.5573-5576.2001

Halonen, S. K., and Weiss, L. M. (2000). Investigation into the mechanism of gamma interferon-mediated inhibition of Toxoplasma gondiiin murine astrocytes. Infect. Immun. 68, 3426-3430. doi: 10.1128/iai.68.6.3426-3430.2000

Hansen, M. B., Nielsen, S. E., and Berg, K. (1989). Re-examination and further development of a precise and rapid dye method for measuring cell growth/cell kill. J. Immunol. Methods 119, 203-210. doi: 10.1016/0022-1759(89)90397-9

Hemphill, A., Vonlaufen, N., and Naguleswaran, A. (2006). Cellular and immunological basis of the host-parasite relationship during infection with Neospora caninum. Parasitology 133, 261-278. doi: 10.1017/s0031182006000485

Innes, E. A., Buxton, D., Maley, S., Wright, S., Marks, J., Esteban, I., et al. (2000). Neosporosis. Aspects of epidemiology and host immune response. Ann. N Y Acad. Sci. 916, 93-101. doi: 10.1111/j.1749-6632.2000.tb05278.x

Innes, E. A., Panton, W. R., Marks, J., Trees, A. J., Holmdahl, J., and Buxton, D. (1995). Interferon gamma inhibits the intracellular multiplication of Neospora caninum, as shown by incorporation of 3H uracil. J. Comp. Pathol. 113, 95-100. doi: 10.1016/s0021-9975(05)80075-1

Jesus, E. E., Pinheiro, A. M., Santos, A. B., Freire, S. M., Tardy, M. B., El-Bachá, R. S., et al. (2013). Effects of IFN- $\gamma$, TNF- $\alpha$, IL-10 and TGF- $\beta$ on Neospora caninum infection in rat glial cells. Exp. Parasitol. 133, 269-274. doi: 10.1016/j.exppara. 2012.11.016

Jolley, W. R., McAllister, M. M., Mcguire, A. M., and Wills, R. A. (1999). Repetitive abortion in Neospora-infected ewes. Vet. Parasitol. 82, 251-257. doi: 10. 1016/s0304-4017(99)00017-5

Jun, C. D., Kim, S. H., Soh, C. T., Kang, S. S., and Chung, H. T. (1993). Nitric oxide mediates the toxoplasmastatic activity of murine microglial cells in vitro. Immunol. Invest. 22, 487-501. doi: 10.3109/08820139309084178

Kerschensteiner, M., Meinl, E., and Hohlfeld, R. (2009). Neuro-immune crosstalk in CNS diseases. Neuroscience 158, 1122-1132. doi: 10.1016/j.neuroscience.2008. 09.009

Khan, I. A., Schwartzman, J. D., Fonseka, S., and Kasper, L. H. (1997). Neospora caninum: role for immune cytokines in host immunity. Exp. Parasitol. 85, 24 34. doi: 10.1006/expr.1996.4110

Kitayama, M., Ueno, M., Itakura, T., and Yamashita, T. (2011). Activated microglia inhibit axonal growth through RGMa. PLoS One 6:e25234. doi: 10.1371/journal. pone. 0025234

Kobayashi, Y., Yamada, M., Omata, Y., Koyama, T., Saito, A., Matsuda, T., et al. (2001). Naturally-occurring Neospora caninum infection in an adult sheep and her twin fetuses. J. Parasitol. 87, 434-436. doi: 10.1645/00223395(2001)087\%5B0434:NONCII\%5D2.0.CO;2

Lagrange, P., Romero, I. A., Minn, A., and Revest, P. A. (1999). Transendothelial permeability changes induced by free radicals in an in vitro model of the blood-brain barrier. Free Radic. Biol. Med. 27, 667-672. doi: 10.1016/s08915849(99)00112-4

Levi, G., Minghetti, L., and Aloisi, F. (1998). Regulation of prostanoid synthesis in microglial cells and effects of prostaglandin E2 on microglial functions. Biochimie 80, 899-904. doi: 10.1016/s0300-9084(00)88886-0

Liberto, C. M., Albrecht, P. J., Herx, L. M., Yong, V. W., and Levison, S. W. (2004). Pro-regenerative properties of cytokine-activated astrocytes. J. Neurochem. 89, 1092-1100. doi: 10.1111/j.1471-4159.2004.02420.x

Malaguti, J. M. A., Cabra, A. D., Abdalla, R. P., Salgueiro, Y. O., Galleti, N. T. C., Okuda, L. H., et al. (2012). Neospora caninum as causative agent of bovine encephalitis in Brazil. Rev. Bras. Parasitol. Vet. 21, 48-54. doi: 10.1590/s198429612012000100010

Minghetti, L., and Levi, G. (1998). Microglia as effector cells in brain damage and repair: focus on prostanoids and nitric oxide. Prog. Neurobiol. 54, 99-125. doi: 10.1016/s0301-0082(97)00052-x

Nishikawa, Y., Tragoolpua, K., Inoue, N., Makala, L., Nagasawa, H., Otsuka, H., et al. (2001). In the absence of endogenous gamma interferon, mice acutely infected with Neospora caninumsuccumb to a lethal immune response characterized by inactivation of peritoneal macrophages. Clin. Diagn. Lab. Immunol. 8, 811-817. doi: 10.1128/cdli.8.4.811-817.2001

Ouyang, W., Rutz, S., Crellin, N. K., Valdez, P. A., and Hymowitz, S. G. (2011). Regulation and functions of the IL-10 family of cytokines in inflammation and disease. Annu. Rev. Immunol. 29, 71-109. doi: 10.1146/annurev-immunol031210-101312

Pinheiro, A. M., Costa, S. L., Freire, S. M., Almeida, M. A., Tardy, M., El Bachá, R., et al. (2006a). Astroglial cells in primary culture: a valid model to study Neospora caninum infection in the CNS. Vet. Immunol. Immunopathol. 15, 243247. doi: 10.1016/j.vetimm.2006.05.006

Pinheiro, A. M., Costa, S. L., Freire, S. M., Meyer, R., Almeida, M. A., Tardy, M., et al. (2006b). Neospora caninum: infection induced IL-10 overexpression in rat astrocytes in vitro. Exp. Parasitol. 112, 193-197. doi: 10.1016/j.exppara.2005.10. 008

Pinheiro, A. M., Costa, S. L., Freire, S. M., Ribeiro, C. S., Tardy, M., El-Bachá, R. S., et al. (2010). Neospora caninum: early immune response of rat mixed glial cultures after tachyzoites infection. Exp. Parasitol. 124, 442-447. doi: 10.1016/j. exppara.2009.12.018

Poli, A., Mancianti, F., Carli, M. A., Stroscio, M. C., and Kramer, L. (1998). Neospora caninum infection in a Bernese cattle dog from Italy. Vet. Parasitol. 78, 79-85. doi: 10.1016/s0304-4017(98)00135-6

Reichel, M. P., Ellis, J. T., and Dubey, J. P. (2007). Neosporosis and hammondiosis in dogs. J. Small Anim. Pract. 48, 308-312. doi: 10.1111/j.1748-5827.2006. 00236.x 
Rosenfeld, G. (1947). Corante pancrômico para hematologia e citologia clínica: nova combinação dos componentes do May Grunwald e do Giemsa num só corante de emprego prático. Memórias do Instituto Butantã 20, 329-335.

Rozenfeld, C., Martinez, R., Figueiredo, R. T., Bozza, M. T., Lima, F. R., Pires, A. L., et al. (2003). Soluble factors released by Toxoplasma gondii-infected astrocytes down-modulate nitric oxide production by gamma interferon-activated microglia and prevent neuronal degeneration. Infect. Immun. 71, 2047-2057. doi: 10.1128/iai.71.4.2047-2057.2003

Rozenfeld, C., Martinez, R., Seabra, S., Sant'Anna, C., Gonçalves, J. G., Bozza, M., et al. (2005). Toxoplasma gondiiprevents neuron degeneration by interferongamma-activated microglia in a mechanism involving inhibition of inducible nitric oxide synthase and transforming growth factor-betal production by infected microglia. Am. J. Pathol. 167, 1021-1031. doi: 10.1016/s00029440(10)61191-1

Scheidegger, A., Vonlaufen, N., Naguleswaran, A., Gianinazzi, C., Müller, N., Leib, S. L., et al. (2005). Differential effects of interferon-gamma and tumor necrosis factor-alpha on Toxoplasma gondii proliferation in organotypic rat brain slice cultures. J. Parasitol. 91, 307-315. doi: 10.1645/ge-379r

Sofroniew, M. V., and Vinters, H. V. (2010). Astrocytes: biology and pathology. Acta Neuropathologica 119, 7-35. doi: 10.1007/s00401-009-0619-8

Spekker, K., Czesla, M., Ince, V., Heseler, K., Schmidt, S. K., Schares, G., et al. (2009). Indoleamine 2,3-dioxygenase is involved in defense against Neospora caninumin human and bovine cells. Infect. Immun. 77, 4496-4501. doi: 10. 1128/IAI.00310-09

Tanaka, T., Nagasawa, H., Fujisaki, K., Suzuki, N., and Mikami, T. (2000). Growth-inhibitory effects of interferon-gamma on Neospora caninum in murine macrophages by a nitric oxide mechanism. Parasitol. Res. 86, 768-771. doi: 10 . 1007/s004360000242

Vonlaufen, N., Gianinazzi, C., Müller, N., Simon, F., Björkman, C., Jungi, T. W., et al. (2002). Infection of organotypic slice cultures from rat central nervous tissue with Neospora caninum: an alternative approach to study host-parasite interactions. Int. J. Parasitol. 32, 533-542. doi: 10.1016/s0020-7519(01)00351-4
Wang, Y., Lin, S. Z., Chiou, A. L., Williams, L. R., and Hoffer, B. J. (1997). Glial cell line-derived neurotrophic factor protects against ischemia-induced injury in the cerebralcortex. J. Neurosci. 17, 4341-4348.

Wouda, W., Moen, A. R., and Schukken, Y. H. (1998). Abortion risk in progeny of cows after a Neospora caninum epidemic. Theriogenology 49, 1311-1316. doi: 10. 1016/s0093-691x(98)00078-8

Yamane, I., Kitani, H., Kokuho, T., Shibahara, T., Haritani, M., Hamaoka, T., et al. (2000). The inhibitory effect of interferon gamma and tumor necrosis factor alpha on intracellular multiplication of Neospora caninum in primary bovine brain cells. J. Vet. Med. Sci. 62, 347-351. doi: 10.1292/jvms.62.347

Zhang, J., and Rivest, S. (2001). Anti-inflammatory effects of prostaglandin E2 in the central nervous system in response to brain injury and circulating lipopolysaccharide. J. Neurochem. 76, 855-864. doi: 10.1046/j.1471-4159.2001. 00080.x

Conflict of Interest Statement: The authors declare that the research was conducted in the absence of any commercial or financial relationships that could be construed as a potential conflict of interest.

Received: 31 May 2014; accepted: 02 October 2014; published online: 27 October 2014 Citation: De Jesus EEV, Dos Santos AB, Ribeiro CSO, Pinheiro AM, Freire SM, ElBachá RS, Costa SL and de Fatima Dias Costa M (2014) Role of IFN- $\gamma$ and LPS on neuron/glial co-cultures infected by Neospora caninum. Front. Cell. Neurosci. 8:340. doi: $10.3389 /$ fncel.2014.00340

This article was submitted to the journal Frontiers in Cellular Neuroscience.

Copyright (C) 2014 De Jesus, Dos Santos, Ribeiro, Pinheiro, Freire, El-Bachá, Costa and de Fatima Dias Costa. This is an open-access article distributed under the terms of the Creative Commons Attribution License (CC BY). The use, distribution and reproduction in other forums is permitted, provided the original author(s) or licensor are credited and that the original publication in this journal is cited, in accordance with accepted academic practice. No use, distribution or reproduction is permitted which does not comply with these terms. 